\title{
Health labour market requirements of health professional education in Yemen
}

\author{
Taha Almahbashi ${ }^{1}$, Syed Mohamed Aljunid ${ }^{2}$ and Aniza Ismail ${ }^{3}$
}

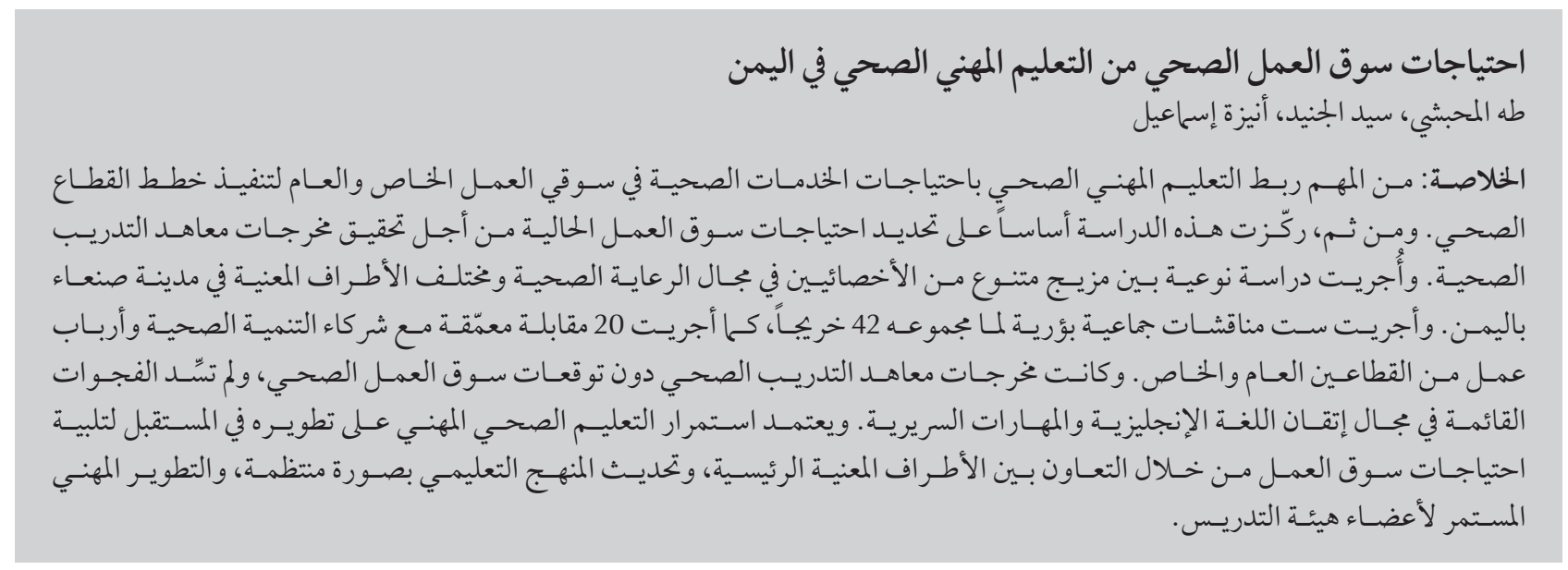

ABSTRACT It is important to link health professional education to the health service needs of the private and public labour market so as to meet the plans of the health sector. Thus, the main focus of this study was to identify the present labour market requirements for the outcomes of health training institutes. A qualitative study was carried out among mixed healthcare professionals and various stakeholders in Sana'a City, Yemen. Six focus group discussions were formed for 42 graduates and 20 in-depth interviews were undertaken with health development partners and public and private employers. Outcomes of the health training institutes were still below the expectations of the health labour market, and did not fill the existing gaps in English-language proficiency and clinical skills. The survival of health professional education depends on future development to meet labour market demands through collaboration between key stakeholders, regular updating of the curriculum, and constant professional development of the teaching staff.

\section{Exigences du marché du travail de la santé et éducation des professionnels de la santé au Yémen}

RÉSUMÉ Il est important d'associer l'éducation des professionnels de la santé aux besoins en matière de services de santé du marché du travail privé et public, de façon à répondre aux aspirations du secteur de la santé. Ainsi, l'objectif premier de la présente étude était d'identifier les exigences du marché du travail actuel afin d'améliorer les résultats des instituts de formation en santé. Une étude qualitative a été menée parmi des professionnels des soins de santé de différentes spécialisations et diverses parties prenantes dans la ville de Sanaa, au Yémen. Six groupes de discussion ont été constitués pour 42 diplômés et 20 entretiens approfondis ont été conduits en collaboration avec des partenaires du développement sanitaire et des employeurs publics et privés. Les résultats des instituts de formation en santé restent en deçà des exigences du marché du travail de la santé, et ne comblaient pas les lacunes en anglais ou en matières de compétences cliniques. La survie de l'éducation des professionnels de la santé dépend des évolutions futures qui seront opérées en vue de répondre aux exigences du marché du travail, grâce à la collaboration entre les parties prenantes clés, une mise à jour régulière des programmes, et le développement professionnel constant des équipes de formation. 


\section{Introduction}

In Yemen and many other parts of the world, there is a growing concern about the fitness of healthcare graduates to provide quality professional services, and the capacity of educational programmes to give nurses and midwives the right set of competencies and ethical and professional values $(1-3)$. In preparing the workforce, the curriculum is expected to meet standards that are often defined as core competencies. The curriculum must also be responsive to changes in health knowledge as well as the needs and demands emerging from health systems. A complete picture of the health labour market includes productivity and performance. Productivity measures the units of care or service that workers provide. Performance is often measured by examining what the health workers are trained to do and how their performance utilizes that training. Performance of health workers includes the quality of their work, the technical skills they use, the care they deliver and the impact of their work on health outcomes (4). Employers are critical that most of the graduates lack the necessary core skills needed to be successful at work, which is attributed to the traditional teaching and learning processes in the education system (5).

A lot of health-related suffering in Yemen is prevented, alleviated or cured by nurses and paramedics, as well as physicians. Most training for health professionals in Yemen is provided by the High Institute of Health Sciences (HIHS), Sana'a and Aden, which is affiliated to the Ministry of Public Health and Population. HIHS has a branch in almost every governorate, and the educational programmes are established according to the needs of the community and capacity of health training institutes. Capacity in pre-service training includes physical infrastructure (e.g., classrooms, laboratories, libraries, clinics for internships, and campus residencies); human resources (quantity and quality of instructors and auxiliary staff); financial resources; organizational and operational capacity (managerial structure and processes); and other non-infrastructure physical inputs (e.g., reference books, journals and computer equipment [1]).

There are scant data at the national level in the Middle Eastern Region regarding the needs of the health labour market and the response of health professional education. This is believed to be the first study in Yemen in the area of health professional education. The unique nature of the study lies in the participation of various players: healthcare professionals (graduates), health development partners, and public and private employers. We used focus group discussions and interviews to identify the needs of the health labour market. Finally, the study links the performance of health professionals with the satisfaction of health development partners and public and private health sector employers.

\section{Methods}

This study was carried out from November 2013 to February 2014. Sana'a, the capital city of Yemen, was selected from among the 21 administrative divisions because it has the largest hospitals and numerous national employers and international health partners. Major public and private hospitals as well as health development partners were selected to generalize the study at the national level.

\section{Interviews}

Twenty in-depth interviews were conducted with the main stakeholders. There were two types of stakeholders: public and private employers and developmental partners who have a direct relationship with health professional education and health institutes. The health development partners who were interviewed were programme and project managers at their organizations and had experience in dealing with the health training institutes. Participants were United Nations and international organizations that have health projects in Yemen (Table 1). The employers' in-depth individual interviews were conducted with representatives in the public and private health sectors that benefit from graduates of the health training institutes (Table 2). An audiotape in-depth interview was conducted through an interview guide that aimed to explore: 1) stakeholders' opinions about the professionalism of graduates of health training institutes and the relevance of healthcare professionals to the labour market; and 2) stakeholders' views of any shortcomings in the healthcare professionals, both in quality and quantity.

\section{Discussion groups}

Six discussion groups were formed for 42 (27 male and 15 female) healthcare professionals: 3 for healthcare professionals working in 3 public referral hospitals and 3 for healthcare professionals working in 3 major private hospitals in Sana' a (Table 3). The characteristics of the healthcare professionals are shown in Table 4. The discussions focused on the healthcare professionals' opinions on the following open-ended questions: 1) How will they prepare academically and professionally to hold their first job in the area of their specialization? 2) How do they see the development of their career after graduation? The discussions were audiotaped with permission from the participants. The discussion moderator was supported by a note-taker during each session. These notes served as supplementary documentation of the discussion, as well as a back-up. A summary of the points discussed in each group session was emailed to participants to verify that the findings were their own views and not those of the researcher. Immediately after each focus group discussion, the moderator, note-taker and researcher 


\begin{tabular}{|c|c|c|}
\hline Entity & Designation & $\begin{array}{c}\text { Main fields of partnership with the health } \\
\text { training institutes }\end{array}$ \\
\hline EU Project & $\begin{array}{l}\text { Member of the technical team of the } \\
\text { project }\end{array}$ & Capacity building in reproductive health \\
\hline WHO & Health System Programmes Officer & $\begin{array}{l}\text { Capacity building and curriculum } \\
\text { development }\end{array}$ \\
\hline UNFPA & $\begin{array}{l}\text { Advocacy and Stimulus Programmes } \\
\text { Officer in Reproductive Health }\end{array}$ & Capacity building and infrastructure support \\
\hline UNICEF & Nutrition Projects Officer & Capacity building in nutrition \\
\hline USAID & MCHIP Manager & Midwifery curriculum development \\
\hline SFD & Health Projects Officer & $\begin{array}{l}\text { Capacity building and education system } \\
\text { support }\end{array}$ \\
\hline $\begin{array}{l}\text { Health and Population Project, the } \\
\text { World Bank }\end{array}$ & Project Manager & Capacity building in midwifery \\
\hline GIZ & Deputy Programme Manager & $\begin{array}{l}\text { Quality improvement programme in health } \\
\text { institutes }\end{array}$ \\
\hline
\end{tabular}

EU = European Union; GIZ = Gesellschaft für Internationale Zusammenarbeit; SFD = Social Fund for Development; UNFPA = United Nations Population Fund; UNICEF = United Nations Children's Fund; USAID = United States Agency for International Development; WHO = World Health Organization.

met for a debriefing session to discuss overall findings.

\section{Data analysis}

To make the data manageable and useful, they were simplified into significant themes and categories that described the phenomena being studied. According to the content analysis, the transcript was read repeatedly for familiarization and then categorized into words and phrases to find meaningful relationships between the categories and emergent themes. The themes that emerged were then related to the study objectives. Triangulation used multiple perspectives to interpret a single set of data to check the validity of the information gathered. A simple method of triangulation was for two colleagues to read and analyse the same set of transcripts and then compare notes. If the notes agreed, then the information was credible.

\section{Results}

The major themes identified from the interviews and the focus group discussions are summarized in Table 5, namely professional performance, career development, academic preparation and linking the outcomes to the needs of the health sector.

\section{Professional performance}

Most employers and health development partners had the opinion that the professional performance of the healthcare professionals was good and satisfactory/good, with some negative observations. These included that Yemeni health professionals demonstrated impatience towards their patients, which differed from the attitude of Indian and Filipino nurses. There was a consensus among all respondents that shortcomings were mainly in the practical skills in all specializations, which was attributed to the limited practical training and inability to deal with modern equipment. These shortcomings were particularly evident in the specializations of radiography and in emergency, intensive care nursing. There were also deficiencies in occupational ethics and safety.

\section{Career development}

Some interviewees were of the opinion that the qualifications offered by the health training institutes were not suitable for the needs of the labour market. This resulted in 33 of 42 (78\%) healthcare professionals stating that they were not satisfied with their career development. They believed that the degrees or certificates issued by the health training institutes did not enable them to improve their positions because they could not continue their studies to bachelor degree and above.

\section{Academic preparation}

Most of the healthcare professionals (35/42, 83\%) were not satisfied with their academic and professional preparation to hold their first job in their area of specialization. Twenty-eight of 42 (67\%) participants expressed satisfaction with the theoretical content of their course. However, 39 of 42 (93\%) participants thought that there was a deficiency in their practical training. There was a weakness in coordination between the educational institutes and the health facilities where practical training was undertaken, and there was a shortage and lack of updating of equipment and tools required for practical training. Some thought that they encountered situations that were more advanced than those studied and 


\begin{tabular}{ll}
\hline Table 2 Health employers interviewed & \\
\hline Entity & \\
\hline Military Hospital in Sana'a & Head of the Nursing Department \\
\hline Al-Jomhori Teaching Hospital & Deputy for Academic Affairs \\
Al-Thawra Modern General Hospital & Head of Nursing Staff \\
Health and Population Office, Al-Tahrir District, Municipality & Office Director \\
Secretariat & \\
Health and Population Office - Sana'a Governorate & Reproductive Health Manager \\
Hospital of the University of Science and Technology & Administrative Manager \\
\hline The Yemeni German Hospital & $\begin{array}{l}\text { Technical and Administrative Director - Vice-Chairman of } \\
\text { the Yemen Association for Private Hospitals }\end{array}$ \\
Dr. Abdulkader Al-Mutawakel Specialized Hospital & General Manager \\
Ibn-Sina Hospital & General Manager \\
Azal Hospital & Deputy Technical Director and Head of Radiology \\
& Department \\
\hline
\end{tabular}

practiced during training, and that they only learned theoretically and practically after graduation.

\section{Linking the outcomes to the needs of the health sector}

Most interviewees (15/20) stated that the graduates did not cover the needs of the labour market, particularly in remote tribal areas of Yemen, where access to health services is difficult and the availability of health service providers is rare. They also stated that there was a shortage of female healthcare professionals, especially in radiography and anaesthetics. Respondents thought that healthcare professionals needed to enhance their linguistic skills, especially English. Others stressed the necessity of acquiring the practical rather than language skills that would be needed in later professional practice. Continued professional development for health care professionals was referred to by most of the participants, with one stating that it made no sense for graduates of health training institutes to continue depending on what they learned 20 years ago. One respondent stated that when the population size and the number of workers are taken into consideration, there is still a need for educational institutions to train more healthcare professionals. Some participants emphasized the need to link the outcomes of health training institutes to the needs of the health sector, but this was not happening at present. One participant stressed the importance of responding to the needs of the health sector market, and raised the challenge of how we can match outcomes to our expectations of the health system.

\section{Discussion}

The perspectives of graduates and employers have been used in several studies to investigate the needs of the labour market in health profession education $(4,5)$. Lack of proficiency in English language was behind the unemployment of 8000 nursing graduates in Malaysia who had not secured jobs, which indicates that a special English course is needed for the nursing profession (6). The importance of English language in the labour market has been indicated in several studies $(7,8)$. The low performance in clinical skills is attributed to several reasons; one of which is that

\begin{tabular}{lccc}
\hline Table 3 Characteristics of hospitals that hosted discussion groups & & & \\
\hline Hospital & Type & No. of beds & Teaching status \\
Al-Jomhori Teaching Hospital & Public & 367 & Major \\
Al-Thawra Modern General Hospital & Public & 500 & Major \\
Dr. Abdulkader Al-Mutawakel Specialized Hospital & Private & 150 & Moderate to limited \\
Saudi German Hospital & Private & 420 & Moderate \\
University Kuwait Hospital & Public & 297 & Major \\
University of Science and Technology Hospital & Private & 350 & Major \\
\hline
\end{tabular}

Source: Ministry of Public Health and Population. Annual health statistical report 2014. Sana'a Yemen. 2014. http://www.mophp-ye.org/arabic/docs/Report2014.pdf. 


\begin{tabular}{|c|c|c|c|c|}
\hline \multirow[t]{2}{*}{ Specialization } & \multicolumn{2}{|c|}{ Gender } & \multirow[t]{2}{*}{ Mean age, yr } & \multirow{2}{*}{$\begin{array}{c}\text { Average years of } \\
\text { experience }\end{array}$} \\
\hline & Male & Female & & \\
\hline Nursing & 8 & 5 & 32 & 8 \\
\hline Medical assistant & 4 & 2 & 27 & 4 \\
\hline Health statistics & 3 & 1 & 30 & 6 \\
\hline Operating Theatre & 2 & 0 & 37 & 11 \\
\hline Radiography & 3 & 1 & 27 & 4 \\
\hline Medical laboratories & 5 & 2 & 26 & 3 \\
\hline Midwifery & 0 & 4 & 28 & 5 \\
\hline Public health & 2 & 0 & 33 & 9 \\
\hline
\end{tabular}

the teaching and training approaches at health training institutions are still teacher- rather than student-centred.

According to the interviewed partners in our study, updating the curricula is the main key to improving the performance of health service providers; however, private employers said that this approach is outdated and has several shortcomings. Updating the curriculum was addressed in the recent National Strategy of Human Resources for Halth in Yemen (2014-2020) as a prominent challenge for the pre-service education sector (9). The World Health Organization (WHO) has reported that health professionals' education and training institutions should consider adapting curricula to population needs, through identifying and defining the core competencies that are required to meet the evolving needs of their populations (1). This seems to explain why the curricula lag behind the real needs of the market and are sometimes not adapted to the capacity of the students. Budget allocations remain an important unresolved concern for curricular development. Some partners have provided financial support to health training institutes for development of some curricula, but there are still some that need updating. It is reported that the level of financial support directly affects curricular development (10). Thus, lack of experience, less productivity and financial shortage are behind the slow pace of curricular development.

In our focus group discussions, the graduates agreed that the teaching aids used at their health training institutions were out of date. Problems occurred when they went to work at hospitals and found things different from what they had studied. This might be attributed to two main reasons: timetable mismanagement, which meant that students had no time to access the library or repeat their training sessions in a skills laboratory; or lack of finance to renew or provide new technology. Such results are consistent with a Kenyan study that showed that providing students with appropriate learning resources increased the quality of university graduates (11).

Education, according to the human science model (12), builds a knowledge and theoretical base that can be transferred and used in other areas to continue growth and learning. In health

\begin{tabular}{ll}
\hline Table 5 Themes emerging from interviews with stakeholders and focus group discussions with healthcare professionals \\
\hline Major themes identified & Key findings \\
Professional performance & - Impatience toward patients \\
& - Limited practical skills \\
& - Inability to deal with modern equipment \\
Career development & - Diciency in job ethics and occupational safety \\
& - Diploma holders are in need of upgrading \\
Academic preparation & - Healthcare professionals are not satisfied with their career development \\
& - Deficiency in practical training \\
Linking the outcomes to the needs of the health & - Shortage of and lack of updating to equipment and tools of practical training \\
sector & - Shortage of female healthcare providers \\
& - Inadequate linguistic competencies
\end{tabular}


care, education focuses on personal development as well as training in the necessary skills and procedures with which health professionals must be familiar. The educational process forms a continuous cycle that involves 2 independent players, the teacher and learners (13). The present study showed that graduates were not satisfied with the performance of their teachers and the teaching methods. The employers also commented that teaching staff did not update their knowledge and need to be trained in teaching methodology. Some teachers may believe that being a good clinician or scientist is sufficient qualification to be a good teacher (14, 15). Without formal preparation for the teaching role, teachers may lack the confidence needed to use unfamiliar teaching techniques. WHO recommends that health professionals' education and training institutions should consider designing and implementing continuous development programmes for teaching staff (1). There is substantial evidence that educators of health professionals are insufficiently prepared in terms of knowledge and skills (16). Another factor that may contribute to poor performance of teaching staff is the selection criteria, and there is not much evidence for strategies or requirements for faculty selection. A major problem is that there is a shortage of educators, particularly in the geographically peripheral areas. Globally, health education institutions have heavy teaching loads and a shortage of educators, while in poorer countries, the major constraint is a scarcity of qualified medical educators to teach the next generation of professionals (17).

Although the study achieved its aims, there were some limitations. First, because of the time limit, this study was conducted only in the capital city of Yemen. Second, some health professionals were not involved in the focus groups due to their work commitments during the study. Third, the targeted interviewees were the health development partners who had collaborative activities with the health training institutes, while other health sector partners were not involved.

\section{Conclusion}

Monitoring entry into the health workforce requires a high level of collaboration between key stakeholders, including ministries of health, education and finance, health training institutions, professional regulatory bodies and the private sector. We conclude that updating the curricula in practical aspects is essential and should be conducted regularly in health training institutes for labour market adaptation. It is particularly interesting to note that graduates provided similar opinions to employers regarding insufficient speaking and writing skills in English, which are important features of nursing, midwifery and other disciplines. Our findings reveal that the teaching staff are in constant need of learning modern teaching principles, particularly with the development and improvement of needs-based teaching.

\section{Funding: None.}

Competing interests: None declared.

\section{References}

1. Transforming and scaling up health professionals' education and training: World Health Organization guidelines. Geneva: World Health Organization; 2013 (http://apps.who. int/iris/bitstream/10665/93635/1/9789241506502_eng.pdf, accessed 22 March 2017).

2. Sousa A, Scheffler RM, Nyoni J, Boerma T. A comprehensive health labour market framework for universal health coverage. Bull World Health Organ. 2013 Nov 1;91:892-4. PMID:24347720

3. Global standards for the initial education of professional nurses and midwives. Geneva: World Health Organization; 2009 (WHO/HRH/HPN/08.6; http://apps.who.int/iris/ bitstream/10665/44100/1/WHO_HRH_HPN_08.6_eng.pdf, accessed 22 March 2017).

4. Asiyai RI. Challenges of quality higher education in Nigeria in the 21st century. Int J Educ Plan Admin. 2013;3(2):159-72 (https://www.ripublication.com/ijepa/ijepav3n2_07.pdf).

5. Arumugam N, Kaur N. Needs analysis on the importance of English communication skills for medical assistants. J Inst Res S E Asia. 2011;9(1):67-77.

6. Nalini A, Xavier T, Laura CD, Mahendran M. Unemployment among graduate nurses in Malaysia: a case study. Asian Soc Sci. 2014;10(9): 227-33 (http://www.ccsenet.org/journal/ index.php/ass/article/view/36594/20579).

7. Herath HMTS, Ranasinghe A. Labour Market Prospects for Business Graduates in Sri Lanka. Int J Soc Sci Humanit. 2011
May;1(1): 26-30 (http://www.ijssh.org/papers/5-H00086. pdf).

8. Mohammad M. Hussainat, Qasem M. The impact of unemployment on young people in the community: a case study from unemployed perspective. Asian Soc Sci. 2013;9(1):155-64 (http://www.ccsenet.org/journal/index.php/ass/article/ view/23542/15039).

9. Badr E. National Human Resources for Health Strategy for Yemen 2014-2020. An extended executive summary. Sana'a: Yemen Ministry of Public Health and Population; 2014

10. Yates L. From curriculum to pedagogy and back again: Knowledge, the person and the changing world. Pedagogy Cult Soc. 2009;17(1):17-28.

11. Gudo C, Olel M. Oanda, I. University expansion in Kenya and issues of quality education: challenges and opportunities. Int J Bus Soc Sci. 2011;2(20):203-14 (http://www.ijbssnet.com/ journals/Vol_2_No_20_November_2011/22.pdf).

12. Huitt W. Humanism and open education. Educ Psychol Interact. 2009 (http://www.edpsycinteractive.org/topics/affect/ humed.html).

13. Carpenter JA, Bell SK. What do nurses know about teaching patients? J Nurses Staff Dev. 2002 May-Jun;18(3):157-61. PMID:12189998

14. DaRosa DA, Skeff K, Friedland JA, Coburn M, Cox S, Pollart S, et al. Barriers to effective teaching. Acad Med. 2011 Apr;86(4):453-9. PMID:21346500 
15. Hafler JP, Ownby AR, Thompson BM, Fasser CE, Grigsby K Haidet $P$, et al. Decoding the learning environment of medical education: a hidden curriculum perspective for faculty development. Acad Med. 2011 Apr;86(4):440-4. PMID:21346498

16. Holmboe ES, Ward DS, Reznick RK, Katsufrakis PJ, Leslie KM Patel VL, et al. Faculty development in assessment: The missing link in competency-based medical education. Acad Med. 2011 Apr;86(4):460-7. PMID:21346509

17. Frenk J, Chen L, Bhutta ZA, Cohen J, Crisp N, Evans T, et al. Health professionals for a new century: transforming education to strengthen health systems in an interdependent world. Lancet. 2010;376(9756):1923-58. PMID:21112623 